\title{
Effect of ORF119 gene deletion on the replication and virulence of orf virus
}

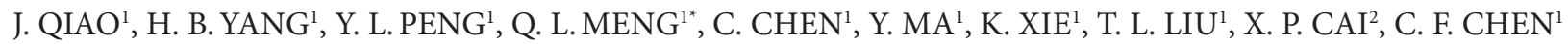

${ }^{1}$ College of Animal Science and Technology, Shihezi University, Shihezi, Xinjiang, 832003, P. R. China; ${ }^{2}$ State Key Lab of Veterinary Etiological Biology, Lanzhou Veterinary Research Institute, Chinese Academy of Agricultural Sciences, Lanzhou, Gansu, 730046, P. R. China

Received September 22, 2014; revised January 20, 2015; accepted August 11, 2015

\begin{abstract}
Summary. - Orf is a severe infectious disease of sheep and goats caused by orf virus (ORFV). To investigate the role of ORF119 gene of ORFV, we constructed ORFV with deleted ORF119 gene and LacZ as reporter gene (ORFV- $\triangle 119$-LacZ) via homologous recombination. The results showed that wild-type ORF-SHZ1 and ORFV$\Delta 119$-LacZ deletion viruses replicated in Vero cells to similar titers. Relative transcriptional levels of virulence genes OVIFNR, GIF, VEGF and VIL-10 of ORFV- $\Delta 119$-LacZ deletion virus were slightly but not significantly lower after $24 \mathrm{hr}$ compared with the wtORF-SHZ1 virus. In vivo experiments showed that 2 -month-old lambs inoculated with ORFV- $\Delta 119$-LacZ deletion virus exhibited a similar total clinical score compared with those inoculated with wtORF-SHZ1 virus. Based on these results, we conclude that deletion of the ORF119 gene has no significant effect on ORFV replication and virulence.
\end{abstract}

Keywords: orf virus; ORF119; gene deletion; replication; virulence

\section{Introduction}

Orf is contagious disease caused by orf virus (ORFV), a member of pox virus family, and occurs mainly in sheep and goats (Haig and Mercer, 1998; Bora et al., 2012). The primary clinical symptoms of orf include erythema, papules, nodules, vesicles, pustules, ulcers and warty thick crust on lips and tongue, nose, skin and mucosa. Lambs at the age of $2-6$ month are the most susceptible animals to ORFV. Cases of orf in wild ungulates (deer and reindeer) and humans have also been reported (Klein et al., 2005; Bayindir et al., 2011; Tryland et al., 2013; Karakas et al., 2013; Nougairede et al., 2013; Zhang et al., 2014). In recent years, orf disease has higher prevalence in many countries and regions with sheep industry (Bora et al., 2012; Chi et al., 2013; Kumar et al., 2014; Oem et al., 2013; Schmidt et al., 2013), especially in

*Corresponding author. E-mail: xjmqlqj@sina.com; qj710625@163. com; phone: 86-993-2055038.

Abbreviations: ORFV = orf virus; OVIFNR = orf virus interferon-resistance gene; GIF = GM-CSF/IL-2 inhibitory factor; VEGF $=$ vascular endothelial growth factor; VIL-10 = viral interleukin 10 ; LacZ = beta-galactosidase some economically underdeveloped areas in China (Li et al., 2012). Secondary infection with other microbial pathogens in sick lambs may result in higher mortality, which causes serious economic losses in sheep industry.

ORFV is double-stranded DNA virus with a genome size of approximately $132-140 \mathrm{~kb}$ and G, C content of $64 \%$. The genome of ORFV is composed of inverted terminal repeats (ORFs 001-008; ORFs 112-134) and coding sequence in the middle region (ORFs009-111) (Delhon et al., 2004). The terminal repeats are variable, while the middle coding region is relatively conserved (McInnes et al., 2001; Billinis et al., 2012). Genome sequence of ORFV indicates that ORFV genome contains 134 open ORFs and ORF119 is located in the right side of the terminal repeat region. So far, however, the role of ORF119 is unclear. In this study, we constructed ORF119 deficient strain using LacZ as reporter gene in order to elucidate the role of ORF119 in ORFV replication and virulence.

\section{Materials and Methods}

Virus and cells. Wild-type ORFV SHZ1 strain (ORFV-SHZ1) was isolated from lamb during an orf outbreak at the animal test station of Shihezi University in 2012. African green monkey kidney (Vero) 
Table 1. PCR primers used in this study

\begin{tabular}{ll}
\hline Primers & Sequence (5' to $\mathbf{3}^{\prime}$ ) \\
\hline P1 & GGCTGCAGGACGGCTACTCCCGCTAATG \\
P2 & GGGACGTCCGTATCCAACTGCTTGCCTC \\
P3 & ATGGACTCTCGTCGGCTCGC \\
P4 & GATTGACCGTAATGGGATAG \\
P5 & TGGGATCTGCCATTGTCAGAC \\
P6 & CCTTCATTGTCCGGTTGAGG \\
DNA polymerase-sense & CAGCATCGACGAGATCGTGG \\
DNA polymerase-anti- & TCGAAGTGGC ACTCTATGTC \\
sense & CGAAGGAGCTCGGCATAT \\
OVIFNR-sense & AACTCGTTGA CCGCACTG \\
OVIFNR-anti-sense & ATGGCGTGCCTCAGAGTGTT \\
GIF-sense & GCCGAGTTGTTATCCGCAG \\
GIF-anti-sense & ATGAAGTTGCTCGTCGGC \\
VEGF-sense & GTCTCGCTTACAGGAACA \\
VEGF-anti-sense & TGGTGTGTGTTGTGATTATT \\
VIL-10-sense & GTGTGAGTAGCATACTGTTC \\
VIL-10-anti-sense &
\end{tabular}

cells were kindly provided by Dr. Wu from Cambridge University and were maintained in Dulbecco's minimal essential medium (DMEM) supplemented with $10 \%$ fetal bovine serum (FBS), 100 $\mu \mathrm{g} / \mathrm{ml}$ streptomycin, $100 \mathrm{U} / \mathrm{ml}$ penicillin, $50 \mu \mathrm{g} / \mathrm{ml}$ gentamicin and $2 \mathrm{mmol} / \mathrm{l} \mathrm{L}$-glutamine. pSC11 vector was provided by Dr. Wu from Cambridge University.

Construction of shuttle vector. Primer sequences for ORF 119 , orf virus interferon-resistance gene (OVIFNR), GM-CSF/ IL-2 inhibitory factor (GIF), vascular endothelial growth factor (VEGF) and viral interleukin (VIL-10) genes were designed by Primer Premier 5.0 software based on the whole genome sequence of ORFV (Acc. No. NC_005336.1) (Table 1). Construction strategy of the recombinant shuttle vector $\mathrm{p} \Delta 119$-LacZ is shown in Fig. 1a. Briefly, genomic DNA from ORFV-SHZ1 was isolated using commercial MiniBEST viral DNA extraction kit (TaKaRa) according the manufacturer's instruction. The homology arm (containing ORFV119 gene) was amplified using primers P1$\mathrm{P} 2$ and inserted to pMD18-T-simple (TaKaRa), generating the recombinant vector $\mathrm{pT}$-ORF119. Vaccinia virus late promoter P11 and reporter gene lacZ from pSC11 vector (Chakrabarti et $a l ., 1985)$ were digested by restriction enzymes SmaI and PstI (TaKaRa) and inserted into pT-ORF119 digested by NotI and SacI (TaKaRa), generating the recombinant vector $\mathrm{p} \Delta 11$ - $\mathrm{LacZ}$. The shuttle vector $\mathrm{p} \Delta 119-\mathrm{LacZ}$ was verified by analysis with restriction enzyme PstI (TaKaRa).

Generation of recombinant ORFV- $\Delta 119$-lacZ virus. Vero cells were cultured in 6-well plates containing DMEM with 10\% FBS (Life Technologies, USA). Vero cells were infected by $100 \mathrm{TCID}_{50}$ of ORFV-SHZ1 virus. Subsequently, the infected cells were transfected with $\mathrm{p} \Delta 11$ - $\mathrm{LacZ}$ shuttle vector using Lipofectamine 2000 (Invitrogen) according to the manufacturer's instructions.
Cells were cultured at $37^{\circ} \mathrm{C}$ with $5 \% \mathrm{CO}_{2}$. The supernatant from cells with cytopathic effect (CPE) was freezed and thawed for 3 times and used to infect the new monolayer of Vero cells. The infected cells were over-laid with an agarose-medium mix and after five days of culture, a further agarose layer containing $\mathrm{X}$-gal (Roche) was added to identify viral plaques expressing the lacZ gene. Recombinant clones were subjected to five rounds of plaque purification until all plaques appeared Lac positive. Viral genomic DNA was isolated from the purified plaques using MiniBEST viral DNA extraction kit (TaKaRa) and used as template to identify ORF119 deletion strain using primers P3-P4 and P5-P6 (producing 1,120 and $750 \mathrm{bp}$ fragment, respectively). Insertion of $\mathrm{P} 11$ promoter from $\mathrm{pSC} 11$ vector and $\mathrm{LacZ}$ in the ORF119 deletion site was confirmed by sequencing three times using the dideoxynucleotide chain termination method with an ABI-PRISM 3730xl Autosequencer (Aplied Biosystems, USA). The DNA sequences that were completely identical at least two times were used for the sequence analysis.

One-step growth curve. Vero cells were inoculated with 10 TCID $_{50}$ of ORFV- $\triangle 119$-LacZ and ORFV-SHZ1. Virus was harvested after $0,3,6,12,24$ and $48 \mathrm{hr}$ of culturing. The median tissue culture infected dose $\left(\mathrm{TCID}_{50}\right)$ per ml was calculated using a spreadsheet. The replication curves of ORFV- $\Delta 119-\mathrm{LacZ}$ and ORFV-SHZ1 were plotted as titer $\left(\log _{10} \mathrm{TCID}_{50} / \mathrm{ml}\right)$ versus time course (hr) post infection. Each experiment was performed with three replicates.

Detection of relative transcriptional levels of virulence gene. Total RNAs were extracted from Vero cells infected with ORFV- $\Delta 119$ LacZ or ORFV-SHZ1 for $24 \mathrm{hr}$ using Trizol (Invitrogen). RNAs were reverse transcribed into cDNA with AMV reverse transcriptase kit (TaKaRa), and used as template in real-time RT-PCR using SYBR Premix Ex TaqTM kit (TaKaRa, Japan) on LightCycler 480 (Roche, Switzerland) according to the manufacturers' instructions. DNA polymerase gene of ORFV was used as internal control. Each sample was tested with three replicates, and then the relative transcript levels of OVIFNR, GIF, VEGF and VIL-10 genes were calculated using $2^{-\triangle \Delta \mathrm{CT}}$ method (Livak and Schmittgen, 2001).

In vivo infection. Two-month-old lambs $(\mathrm{n}=12)$ were divided into three groups with 4 lambs in each group. The first group was inoculated with $0.5 \mathrm{ml}\left(1 \times 10^{5} \mathrm{TCID}_{50} / \mathrm{ml}\right)$ of ORFV- $\Delta 119-\mathrm{LacZ}$ infected Vero cell culture medium on the lip. The second group was inoculated similarly with ORFV-SHZ1 and the third group was inoculated with sterile saline buffer as control. The groups of lambs were separated and observed for four weeks. After the infection, the development of lesions in ORFV- $\Delta 119-\mathrm{LacZ}$ and ORFV-SHZ1 inoculated lambs was compared daily using a clinical scoring procedure (Nettleton et al., 1996).

Statistical analysis. The experimental data were presented as the mean \pm standard deviation from three independent experiments and analyzed by SPSS software. The $t$-test was applied to analysis of the difference between the experimental groups and control groups. A p value of less than 0.05 was considered as a statistically significant difference. 
(a)

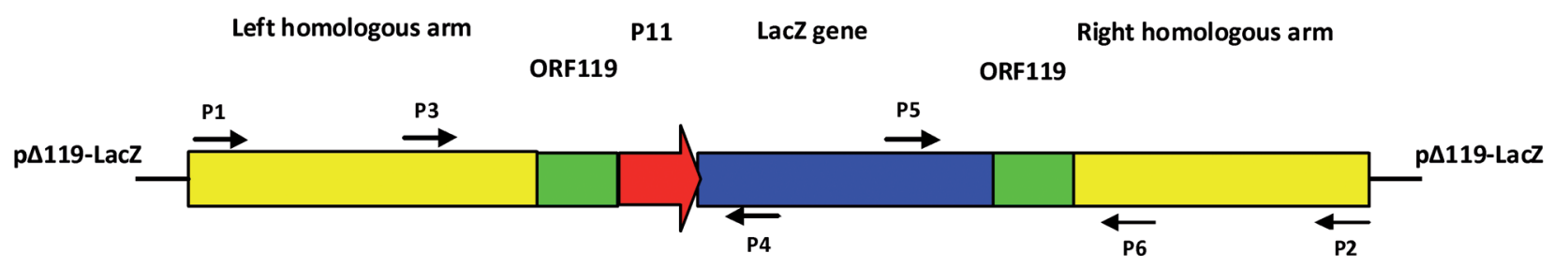

(b)

(c)
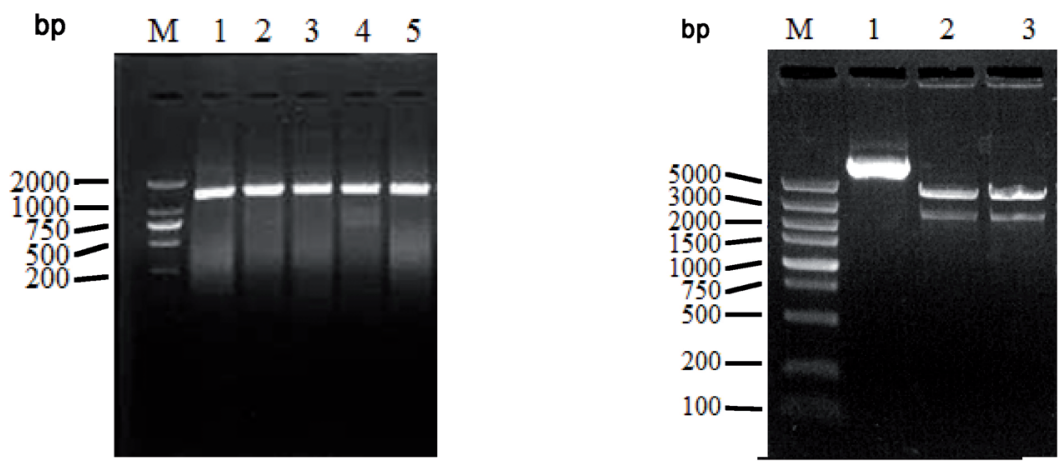

Fig. 1

Construction and identification of the shuttle vector $\mathrm{p} \Delta 119-\mathrm{LacZ}$

(a) Scheme of the shuttle vector $\mathrm{p} \Delta 11$-LacZ. P11 promoter (red arrow), ORF119 gene (green box), left and right arms for homologous recombination (yellow boxes), LacZ gene (blue box), PCR primers (black arrows). (b) PCR amplification of homology arms containing ORFV119 gene. DNA size marker (DL2000) (lane M), ORFV119 gene and homology arm fragment (lanes 1-5). (Cc Identification of recombinant shuttle vector p $\Delta 119$-LacZ digested with PstI. DNA size marker (DL5000) (lane M), p $\Delta 119$-LacZ (lane 1), p $\Delta 119$-LacZ digested with PstI (lanes 2-3).

(a)

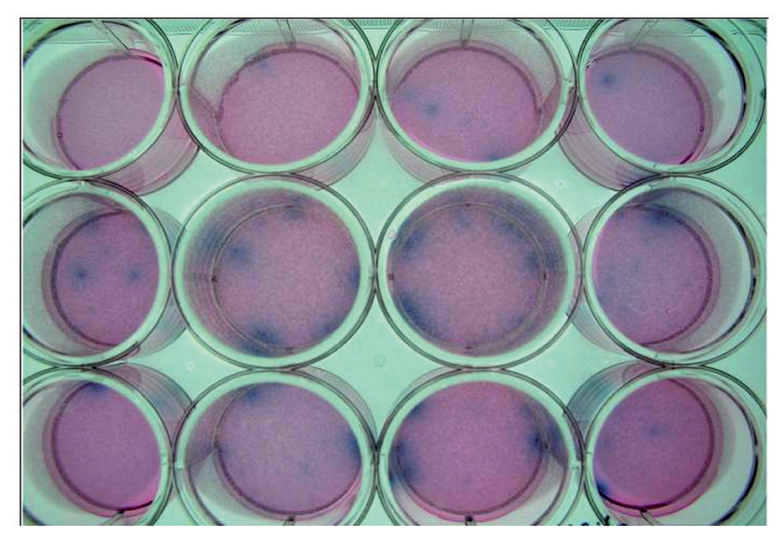

(b)

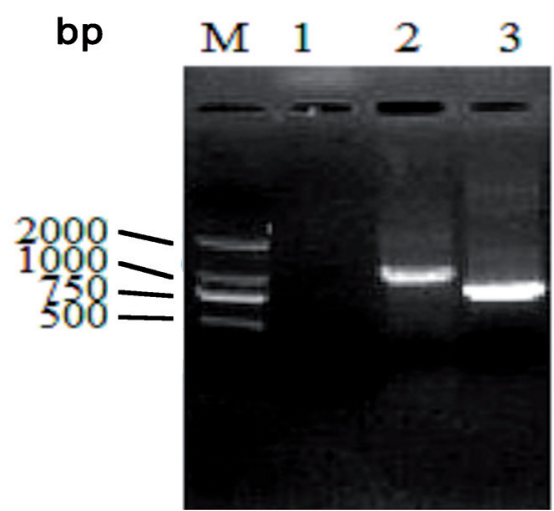

Fig. 2

Generation and identification of recombinant ORFV- $\Delta 119-\mathrm{LacZ}$

(a) Blue plaques of ORFV- $\Delta 119$-LacZ on Vero cells. (b) Identification of ORFV- $\Delta 119$-LacZ by PCR. M: DNA size marker (DL2000) (lane M), amplification of ORFV SHZ1 (lane 1), amplification of ORFV- 11 19-LacZ with primers P3-P4 (lane 2), and P5-P6 (lane 3).

\section{Results}

The homology arm (containing the upstream, downstream and ORFV119 gene) was amplified with an expected size of $1,475 \mathrm{bp}$ (Fig. 1b). The expected size of the shuttle vec- tor $\mathrm{p} \Delta 119$-LacZ containing the upstream and downstream sequences of ORF119, P11 promoter and lacZ reporter gene was $7,7 \mathrm{~kb}$, which was confirmed by restriction digestion using Pst I (producing 2,700 bp and 5,000 bp bands) (Fig. 1c). ORF119 deficiency strain ORFV- $\Delta 119$-LacZ can cause CPE 
ATGGACTCTCGTCGGCTCGCCCTTGCCGTTGCCTTTGGAGGCGTCCTCGCCAGCATGACGCAGCGCCGCCGCCTGG СTTСTСTСATCGCCAGCATCGGCCAACGGTTGATGGGCGGCGACGGCATGCGTCGCGTCGCCGTTCGGTTGATCGA CCAGCTCATGGCCGGACCCCCGGACATCGACGACGAAGCCTTCCAGCGCGAGATCCGCGTGGGCGTGGGCGAGCTC CACCCAATCGTTTAGAAAAGGAAGCCTCCTTAAAGCATTTCATACACACAGCAGTTAGTTTTACCACCATTTCAGA TAATGGAATAAGATTCAAAATATTATTAAACGGTTTACGTTGAAATGTCCСATCGAGTGCGGCTACTATAACTATT TTTCCTTCGTTTGCCATACGCTCACAGAATCCCGGGGATCCGTCACTGTTCTTTATGATTCTACTTCCTTACCGT GCAATAAATTAGAATATATTTTCTACTTTTACGAGAAATTAATTATTGTATTTATTATTTATGGGTGAAAAACTTA СTATAAAAAGCGGGTGGGTTGGAATTAGTGATCAGTTTATGTATATCGCAACTACCGGGCATATGGCTATCGACA TCGAGAACATTACCCACATGATAAGAGATTGTATCAGTTTCGTAGTCTTGAGTATTGGTATTACTATATAGTATAT AGATGTCTAGAAGCGATGCTACGCTAGTCACAATCACCACTTTCATATTTAGAATATATGTATGTAAAAATATAGT AGAATTTCATTTTGTTTTTTTCTATGCTATAAATGAATTCCTCGAGGGATCCCGTCGTTTTACAACGTCGTGACTG GGAAAACCCTGGCGTTACCCAACTTAATCGCCTTGCAGCACATCCCCСTTTCGCCAGCTGGCGTAATAGCGAAGAG GCCCGCACCGATCGCCCTTCCCAACAGTTGCGCAGCCTGAATGGCGAATGGCGCTTTGCCTGGTTTCCGGCACCAG AAGCGGTGCCGGAAAGCTGGCTGGAGTGCGATCTTCCTGAGGCCGATACTGTCGTCGTCCCCTCAAACTGGCAGAT GCACGGTTACGATGCGCCCATCTACACCAACGTGACCTATCCCATTACGGTCAATC

Fig. 3

The nucleotide sequence of left homologous arm fragment of the recombinant ORFV- $\Delta 119$-LacZ

The primer sequence is double-underlined (red); left homologous arm is underlined (blue), and the remaining part is the inserted gene sequences (black).

TGGGATCTGCCATTGTCAGACATGTATACCCCGTACGTCTTCCCGAGCGAAAACGGTCTGCGCTGCGGGACGCGCG AATTGAATTATGGCCCACACCAGTGGCGCGGCACTTCCAGTTCAACATCAGCCGCTACAGTCAACAGCAACTGAT GGAAACCAGCCATCGCCATCTGCTGCACGCGGAAGAAGGCACATGGCTGAATATCGACGGTTTCCATATGGGGATT GGTGGCGACGACTCCTGGAGCCCGTCAGTATCGGCGGAATTCCAGCTGAGCGCCGGTCGCTACCATTACCAGTTGG TCTGGTGTCAAAAATAATAATAACCGGGCAGGGGGGATCCCCGACCTGCAGCCAAGCTCCGAATTCAACAATGTCT GGAAAGAACTGTCCTTCATCGATACCTATCACGGAGAAATCTGTAATTGATTCCAAGACATCACATAGTTTAGTTG СTTCCAATGCTTCAAAATTATTCTTATCATGCGTCCATAGTCCCGTTCCGTACCCCAGCCCGCGCCCCTGGCGATC ACGCCACAGAACGCGTTCATGTTCGTGCCGCAAAGCAGCCACGTGCACGTGGACGAGAGCGTGGACCCGTTCTTCG GCATGAGCCССTCCATCTTCGGGCGCAACATCCCССTTCAGCCGCCCGAGGAGCTGCTGAGCGACTACGACCCGCT CATGAGCCAGGCCGCCCTACCTCACCCACACCCACTCACACCAACACCTCAACCGGACAATGAAGG

Fig. 4

The nucleotide sequence of right homologous arm fragment of the recombinant ORFV- $\Delta 119-\mathrm{LacZ}$ The primer sequence is double-underlined (red); the right homologous arm is underlined (blue), and the remaining part is the LacZ gene sequence (black). 


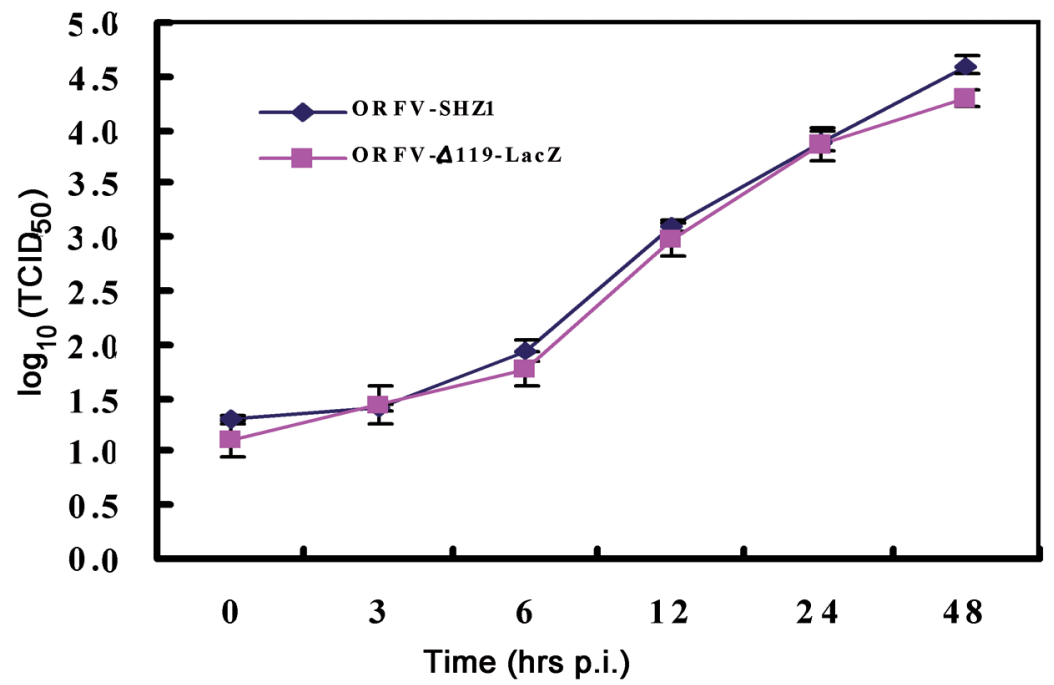

Fig. 5

Replication curves of ORFV-SHZ1 and ORFV- $\triangle 119-\mathrm{LacZ}$ in Vero cells

Data represent averages from three independent experiments. ORFV-SHZ1 (diamonds) ORFV- $\Delta 119$-LacZ (squares), SD (error bars).

in Vero cells and produce blue plaques (Fig. 2a), indicating that the recombinant virus expresses LacZ gene. PCR using primers P3-P4 and P5-P6 yielded bands of expected size of $1,120 \mathrm{bp}$ and $750 \mathrm{bp}$ from ORFV- $\Delta 119$-LacZ, but failed to amplify any band from ORFV-SHZ1 (Fig. 2b). Sequence analysis showed that PCR product amplified with P3-P4 primers contained partial sequences of the upstream ORF119 gene, P11 promoter and LacZ sequences (Fig. 3). The PCR product amplified by primer P5-P6 contained ORF119 downstream and inserted sequences (Fig. 4), indicating that

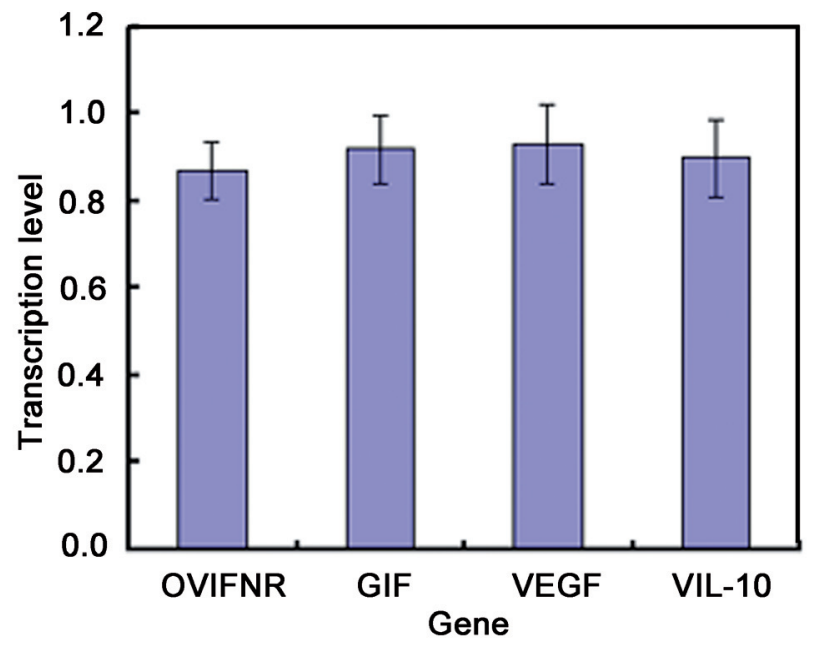

Fig. 6

Relative expression levels of OVIFNR, GIF, VEGF and VIL-10 genes of ORFV- $\Delta 119-\mathrm{LacZ}$ in Vero cells $48 \mathrm{hr}$ post infection
ORF119 deletion strain (ORFV- $\Delta 119$-LacZ) was successfully constructed.

To investigate the replicating ability of ORF119 genedeleted mutant strain, a one-step growth curve was conducted. After $0,3,6,12,24$ and $48 \mathrm{hr}$ of Vero cell infection, TCID $_{50}$ of ORFV- $\Delta 119$-LacZ was slightly lower than that of ORFV-SHZ1. However, statistics showed that there was no significant difference between ORFV-SHZ1 and ORFV$\triangle 119$-LacZ $(P>0.05)$. The replication curve of ORFV- $\Delta 119$ LacZ was similar to that of ORFV-SHZ1 (Fig. 5), suggesting that deletion of ORF119 has no significant effect on the virus replication in Vero cells.

The relative transcriptional levels of virulence genes including OVIFNR, GIF, VEGF and VIL-10 in the ORF119 deletion virus were slightly, but not significantly $(P>0.05)$, lower compared to those in the wild-type virus (Fig. 6), suggesting that ORF119 does not affect the expression of virulence genes of ORFV.

Papules and pustules occurred in the mouth and lips of lambs infected with both ORFV-SHZ1 and ORFV$\Delta 119$-LacZ strain for one week. After two weeks of infection, scabs gradually occurred in both ORFV-SHZ1 and ORFV- $\Delta 119$-LacZ-infected lambs (Fig. 7). In the lambs inoculated with saline buffer, no pathological changes were observed. Lambs inoculated with ORFV- $\Delta 119-\mathrm{LacZ}$ had no significant difference $(P>0.05)$ in total clinical scores in period of observation after infection than that of lambs inoculated with ORFV-SHZ1 (Fig. 8). This suggests that ORF119 has no significant effect on the virulence in vivo. 
(a)

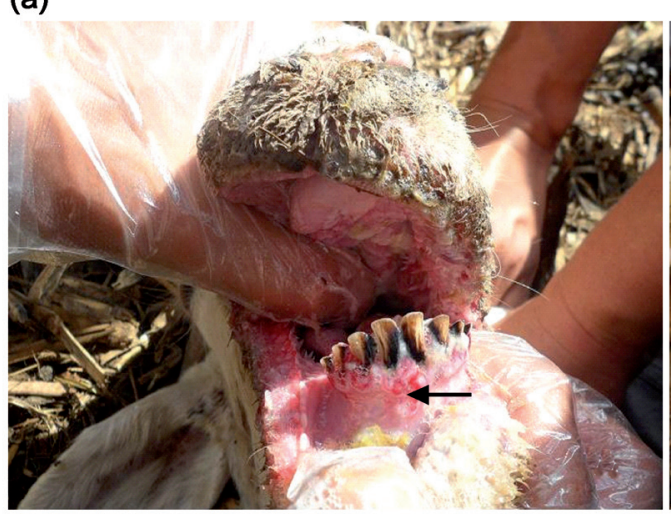

(b)

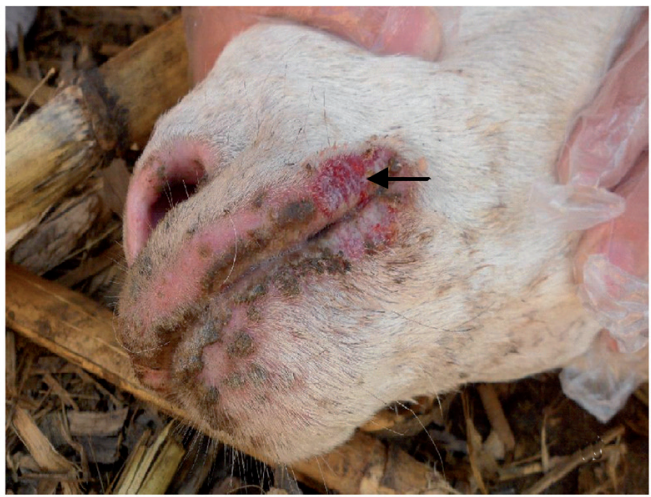

Fig. 7

Clinical symptoms of sheep inoculated with ORFV- $\Delta 119-\mathrm{LacZ}$

Ulceration of gingival mucosa (a) and the lip (b, arrow).

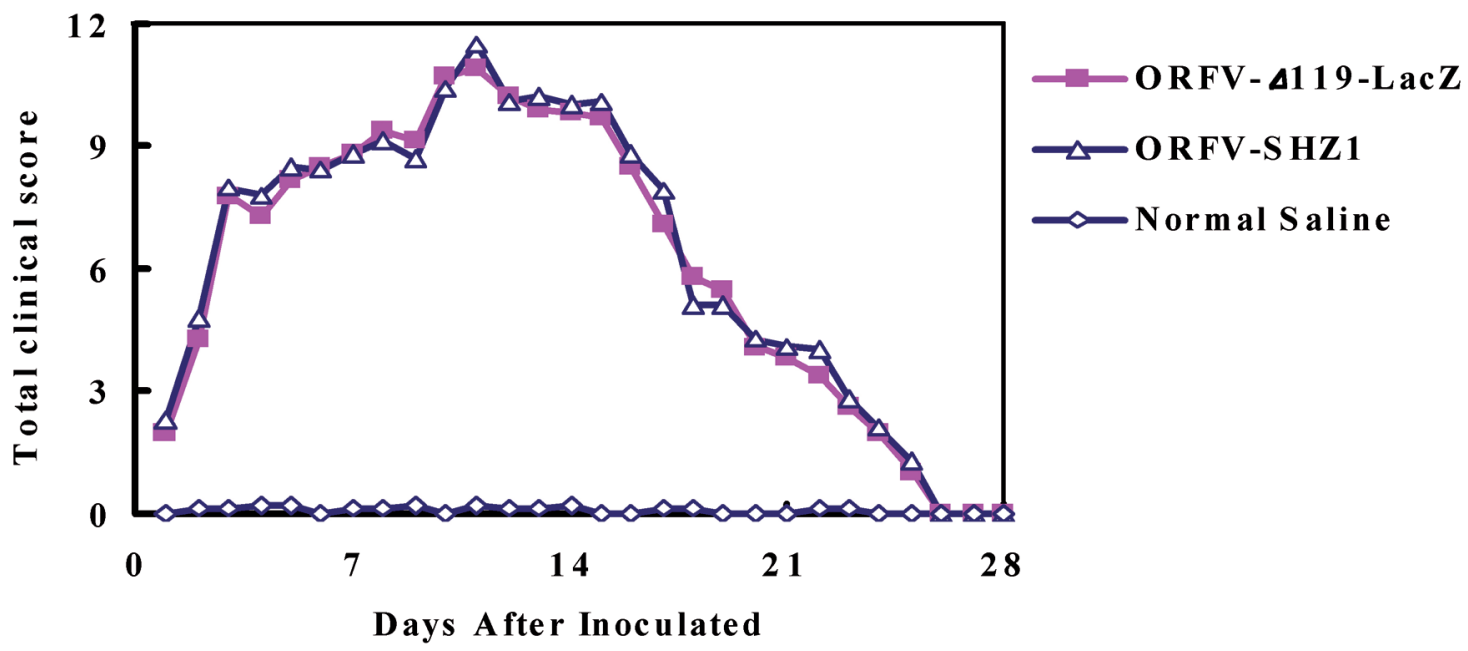

Fig. 8

Total clinical scores in period of observation after inoculation with ORFV-SHZ1 and ORFV- $\triangle 119-\mathrm{LacZ}$ Data show 2-month-old lambs inoculated with ORFV- $\Delta 119$-LacZ deletion virus which exhibited a similar total clinical score compared with those inoculated with wtORF-SHZ1 virus. ORFV-SHZ1 (triangles), ORFV- 11 19-LacZ (squares), saline buffer (diamonds).

\section{Discussion}

Orf is an acute, highly contagious zoonotic disease (Bayindir et al., 2011; Nougairede et al., 2013). Prevention and control of the disease cannot only improve the economic efficiency in sheep industry, but also has important public health implications. Although whole genome sequences for four strains of ORFV (OV-SA00, OV-IA82, NZ2 and D1701) have been deposited in the GenBank, functions of many genes are still poorly understood (Delhon et al., 2004; Friebe et al., 2011). Comparison of the whole genome sequence of sheep ORFV isolate (OVIA82) and goat isolate (OV-SA00) with bovine papular stomatitis virus isolate indicated that ORFV contained 132-134 ORFs (Delhon et al., 2004). Furthermore, virulence and immune regulation-related genes were concentrated at the terminal inverted repeats (ITRs) region of the ORFV genome (Haig and Fleming, 1999; McInnes et al., 2001; Friebe et al., 2011). At present, only some ORFV virulence factors have been confirmed, which include viral interferon inhibitory protein (OVIFN, ORF020) (Haig et al., 1998), chemokine binding protein (CBP, ORF112) (Seet et al., 2003), GM-CSF/IL-2 inhibitory 
factor (GIF, ORF117) (Deane et al., 2000), viral interleukin 10 (VIL-10, ORF127) (Fleming et al., 1997; Chan et al., 2006) and vascular endothelial growth factor (VEGF, ORF132) (Lyttle et al., 1994; Savory et al., 2000). Westphal et al. (2009) utilized vaccinia and ORFV virus recombinant technology to study the biological function of ORF125 and demonstrated that ORF125 is capable of inhibiting the activity of Bcl-2 and apoptosis in the host cells to facilitate viral replication. Diel et al., found that ORF121-encoded protein can inhibit $\mathrm{NF}-\kappa \mathrm{B}$ signaling pathway, thereby inhibiting the secretion of a number of important cytokines and immune response of host cells (Diel et al., 2011). However, the function of many genes encoded by the terminal ITRs (ORFs 001-008 and 112-134) has not been elucidated.

At present, ORFV is proving useful both as an immunomodulator and as a vector for the expression of foreign antigens in non-permissive species (Amann et al., 2013; Fischer et al., 2003; Rohde et al., 2011, 2013; Tan et al., 2012). To understand the function of ORFV replication and virulence-related genes is the premise to develop novel vaccine vectors. However, so far, the role of ORFV 119 has not been reported. In this study, we generated ORF119 deletion strain by homologous recombination and demonstrated that ORF119 does not play an important role in the viral replication in Vero cells. Furthermore, the expression of virulence related genes in the ORF119 deficiency strain was not significantly different from those of the wild type strain. In vivo studies confirmed that both ORF119 deletion and wild type ORFV strains can cause disease in lambs, suggesting that ORF119 is not required for viral replication in host cells and virulence both in vitro and in vivo.

Acknowledgements. This work was supported by grant No. 2014DFR31310 from the International Science \& Technology Cooperation Program of China; grant No. 31360596 and 30960274 from National Natural Science Foundation of China; grant No. 2012BC006 from International Science and Technology Cooperation Program of Xinjiang Production and Construction Corps. The authors thank the field staff for providing the samples for this study.

\section{References}

Amann R, Rohde J, Wulle U, Conlee D, Raue R, Martinon O, Rziha HJ (2013): A new rabies vaccine based on a recombinant ORF virus (parapoxvirus) expressing the rabies virus glycoprotein. J. Virol. 87, 1618-1630. http://dx.doi. org/10.1128/JVI.02470-12

Bayindir Y, Bayraktar M, Karadag N, Ozcan H, Kayabas U, Otlu B, Durmaz R, Doganay M (2011): Investigation and analysis of a human orf outbreak among people living on the same farm. New Microbiol. 34, 37-43.
Billinis C, Mavrogianni VS, Spyrou V, Fthenakis GC (2012): Phylogenetic analysis of strains of Orf virus isolated from two outbreaks of the disease in sheep in Greece. Virol J. 9, 24. http://dx.doi.org/10.1186/1743-422X-9-24

Bora DP, Barman NN, Das SK, Bhanuprakash V, Yogisharadhya R, Venkatesan G, Kumar A, Rajbongshi G, Khatoon E, Chakraborty A, Bujarbaruah KM (2012): Identification and phylogenetic analysis of orf viruses isolated from outbreaks in goats of Assam, a northeastern state of India. Virus Genes 45, 98-104. http://dx.doi.org/10.1007/ s11262-012-0740-y

Chakrabarti S, Brechling K, Moss B (1985): Vaccinia virus expression vector: coexpression of beta-galactosidase provides visual screening of recombinant virus plaques. Mol. Cell Biol. 5, 3403-3409.

Chan A, Baird M, Mercer AA, Fleming SB (2006): Maturation and function of human dendritic cells are inhibited by orf virus-encoded interleukin-10. J. Gen. Virol. 87, 31773181. http://dx.doi.org/10.1099/vir.0.82238-0

Chi X, Zeng X, Hao W, Li M, Li W, Huang X, Wang S, Luo S (2013): Heterogeneity among orf virus isolates from goats in Fujian Province, Southern China. PLoS One 8, e66958. http://dx.doi.org/10.1371/journal.pone.0066958

Deane D, McInnes CJ, Percival A, Wood A, Thomson J, Lear A, Gilray J, Fleming S, Mercer A, Haig D (2000): Orf virus encodes a novel secreted protein inhibitor of granulocytemacrophage colony-stimulating factor and interleukin-2. J. Virol. 74, 1313-1220 http://dx.doi.org/10.1128/ JVI.74.3.1313-1320.2000

Delhon G, Tulman ER, Afonso CL, Lu Z, de la Concha-Bermejillo A, Lehmkuhl HD, Piccone ME, Kutish GF, Rock DL (2004): Genomes of the parapoxviruses ORF virus and bovine papular stomatitis virus. J. Virol. 78, 168-177. http:// dx.doi.org/10.1128/JVI.78.1.168-177.2004

Diel DG, Luo S, Delhon G, Peng Y, Flores EF, Rock DL (2011): Orf virus ORFV121 encodes a novel inhibitor of NF-kappaB that contributes to virus virulence. J. Virol. 85, 2037-2049. http://dx.doi.org/10.1128/JVI.02236-10

Fischer T, Planz O, Stitz L, Rziha HJ (2003): Novel recombinant parapoxvirus vectors induce protective humoral and cellular immunity against lethal herpesvirus challenge infection in mice. J. Virol. 77, 9312-9323. http://dx.doi. org/10.1128/JVI.77.17.9312-9323.2003

Fleming SB, McCaughan CA, Andrews AE, Nash AD, MercerAA (1997): A homolog of interleukin-10 is encoded by the poxvirus orf virus. J. Virol. 71, 4857-4861.

Friebe A, Friederichs S, Scholz K, Janssen U, Scholz C, Schlapp T, Mercer A, Siegling A, Volk HD, Weber O (2011): Characterization of immunostimulatory components of orf virus (parapoxvirus ovis). J. Gen. Virol. 92, 1571-1584. http://dx.doi.org/10.1099/vir.0.028894-0

Haig DM, Fleming S (1999) Immunomodulation by virulence proteins of the parapoxvirus orf virus. Vet. Immunol. Immunopathol. 72, 81-86. http://dx.doi.org/10.1016/ S0165-2427(99)00119-1

Haig DM, McInnes CJ, Thomson J, Wood A, Bunyan K, Mercer A (1998): The orf virus OV20.0L gene product is involved in interferon resistance and inhibits an interferon- 
inducible, double-stranded RNA-dependent kinase. Immunology 93, 335-340. http://dx.doi.org/10.1046/j.13652567.1998.00438.x

Haig DM, Mercer AA (1998): Ovine diseases. Orf. Vet. Res. 29, $311-326$

Karakas A, Oguzoglu TC, Coskun O, Artuk C, Mert G, Gul HC, Sener K, Özkul A (2013): First molecular characterization of a Turkish orf virus strain from a human based on a partial B2L sequence. Arch. Virol. 158, 1105-1108. http://dx.doi.org/10.1007/s00705-012-1575-5

Klein J, Tryland M (2005): Characterisation of parapoxviruses isolated from Norwegian semi-domesticated reindeer (Rangifer tarandus tarandus). Virol. J. 2, 79. http://dx.doi. org/10.1186/1743-422X-2-79

Kumar N, Wadhwa A, Chaubey KK, Singh SV, Gupta S, Sharma S, Sharma DK, Singh MK, Mishra AK (2014): Isolation and phylogenetic analysis of an orf virus from sheep in Makhdoom, India. Virus Genes 48, 312-319. http:// dx.doi.org/10.1007/s11262-013-1025-9

Li W, Ning Z, Hao W, Song D, Gao F, Zhao K, Liao X, Li M, Rock DL, Luo $S$ (2012): Isolation and phylogenetic analysis of orf virus from the sheep herd outbreak in northeast China. BMC Vet. Res. 8, 229. http://dx.doi.org/10.1186/17466148-8-229

Livak KJ, Schmittgen TD (2001): Analysis of relative gene expression data using real-time quantitative PCR and the 2(Delta Delta C(T)) method. Methods 25, 402-408. http:// dx.doi.org/10.1006/meth.2001.1262

Lyttle DJ, Fraser KM, Fleming SB, Mercer AA, Robinson AJ (1994): Homologs of vascular endothelial growth factor are encoded by the poxvirus orf virus. J. Virol. 68, 84-92.

McInnes CJ, Wood AR, Nettleton PE, Gilray JA (2001): Genomic comparison of an avirulent strain of Orf virus with that of a virulent wild type isolate reveals that the Orf virus G2L gene is non-essential for replication. Virus Genes 22, 141-150. http://dx.doi.org/10.1023/A:1008117127729

Nettleton PF, Brebner J, Pow I, Gilray JA, Bell GD, Reid HW (1996): Tissue culture-propagated orf virus vaccine protects lambs from orf virus challenge. Vet. Rec. 138, 184-186. http://dx.doi.org/10.1136/vr.138.8.184

Nougairede A, Fossati C, Salez N, Cohen-Bacrie S, Ninove L, Michel F, Aboukais S, Buttner M, Zandotti C, de Lamballerie X, Charrel RN (2013): Sheep-to-human transmission of Orf virus during Eid al-Adha religious practices, France. Emerg. Infect. Dis. 19, 102-105. http://dx.doi. org/10.3201/eid1901.120421

Oem JK, Chung JY, Kim YJ, Lee KK, Kim SH, Jung BY, Hyun BH (2013): Isolation and characterization of orf viruses from
Korean black goats. J. Vet. Sci. 14, 227-230. http://dx.doi. org/10.4142/jvs.2013.14.2.227

Rohde J, Amann R, Rziha HJ (2013): New Orf virus (Parapoxvirus) recombinant expressing $\mathrm{H} 5$ hemagglutinin protects mice against $\mathrm{H} 5 \mathrm{~N} 1$ and $\mathrm{H} 1 \mathrm{~N} 1$ influenza $\mathrm{A}$ virus. PLoS One 8, e83802. http://dx.doi.org/10.1371/journal. pone. 0083802

Rohde J, Schirrmeier H, Granzow H, Rziha HJ (2011): A new recombinant Orf virus (ORFV, Parapoxvirus) protects rabbits against lethal infection with rabbit hemorrhagic disease virus (RHDV). Vaccine 29, 9256-9264. http:// dx.doi.org/10.1016/j.vaccine.2011.09.121

Savory LJ, Stacker SA, Fleming SB, Niven BE, Mercer AA (2000): Viral vascular endothelial growth factor plays a critical role in orf virus infection. J. Virol. 74, 10699-10706 http:// dx.doi.org/10.1128/JVI.74.22.10699-10706.2000

Schmidt C, Cargnelutti JF, Brum MC, Traesel CK, Weiblen R, Flores EF (2013): Partial sequence analysis of B2L gene of Brazilian orf viruses from sheep and goats. Vet. Microbiol. 162, 245-253. http://dx.doi.org/10.1016/j. vetmic.2012.10.031

Seet BT, McCaughan CA, Handel TM, Mercer A, Brunetti C, McFadden G, Fleming SB (2003): Analysis of an orf virus chemokine-binding protein: Shifting ligand specificities among a family of poxvirus viroceptors. Proc. Natl. Acad. Sci. USA 100, 15137-15142. http://dx.doi.org/10.1073/ pnas. 2336648100

Tan JL, Ueda N, Heath D, Mercer AA, Fleming SB (2012): Development of orf virus as a bifunctional recombinant vaccine: surface display of Echinococcus granulosus antigen EG95 by fusion to membrane structural proteins. Vaccine 30, 398-406. http://dx.doi.org/10.1016/j. vaccine.2011.10.079

Tryland M, Klein J, Berger T, Josefsen TD, das Neves CG, Oksanen A, Åsbakk K (2013): Experimental parapoxvirus infection (contagious ecthyma) in semi-domesticated reindeer (Rangifer tarandus tarandus). Vet. Microbiol. 162, 499506. http://dx.doi.org/10.1016/j.vetmic.2012.10.039

Westphal D, Ledgerwood EC, Tyndall JD, Hibma MH, Ueda N, Fleming SB, Mercer AA (2009): The orf virus inhibitor of apoptosis functions in a Bcl-2-like manner, binding and neutralizing a set of $\mathrm{BH} 3$-only proteins and active Bax. Apoptosis 14, 1317-1330. http://dx.doi.org/10.1007/ s10495-009-0403-1

Zhang K, Liu Y, Kong H, Shang Y, Liu X (2014): Human infection with ORF virus from goats in China, 2012. Vector Borne Zoonotic. Dis. 14, 365-367. http://dx.doi.org/10.1089/ vbz.2013.1445 